\title{
May the Power Be With Us
}

\section{Tomasz Kostka ${ }^{1 *}$ and Joanna Kostka ${ }^{2}$}

${ }^{1}$ Department of Geriatrics, Medical University of Lodz, Poland

2 Joanna Kostka, Department of Physical Medicine, Medical University of Lodz, Poland

May the Force be with you" was a famous Star Wars phrase used to wish luck or express good will. It bestowed the power of the Force upon the addressee, especially before a battle. Used originally by Jedi Knights and repeated for many years by millions of their teenage fans, the phrase can nowadays be repeated by older Star Wars enthusiasts and their peers with a new meaning-to convey good luck and hope for the fight against aging. This fight is not primarily with death, the inevitable final outcome of our earthly struggle, but with functional decline and disability in later life. And this battle is usually not lost. An increasing body of scientific research regarding functional capacity concerns older people and the declining level of functional status with advancing age [1-3]. Physical disability due to aging, prevalent diseases and an inactive lifestyle can lead to a loss of ability in performing the basic activities of daily living, and consequently, to the loss of independence in daily life [3]. Lack of independence in those activities is a predictor of falls [4], institutionalization [1], hospitalization [5], worse quality of life and increased mortality $[2,6]$. Therefore, it is very important to know the factors determining the functional performance of older patients and build preventive and rehabilitation programs designed to improve those dimensions that have the greatest impact on functional health. The condition of the skeletal muscles is one of the most important predictors of functional capacity in advanced age, but the varied properties of the muscles may have different meanings.

\section{Muscle Strength}

It is known that skeletal muscle function becomes gradually impaired with advancing age [7]. The age-related decline of neuromuscular functioning is related mainly to muscle loss (sarcopenia), changes in muscle quality and neuromuscular control. The relative contribution of the progressive reduction of muscle mass (sarcopenia) and decreasing muscle quality to this age-related decline in muscle performance remains uncertain [8]. As muscular strength is mainly dependent on the cross-sectional area of the muscle [9], the decrease occurring in muscle mass with age results in the decline of their strength, although quantitative changes of muscles with age do not fully explain this decline in muscle strength [8]. Infiltration of muscle by fat tissue in well functioning older persons is associated with poorer muscle function than could not be expected only from the volume of muscle [10]. The majority of studies investigating age-related changes in muscle function have assessed muscle mass and strength (force). Age-associated decline of muscle strength has usually been depicted as linear or curvilinear, with acceleration after the fifth decade [11]. The role of muscle strength in maintaining independence in daily functioning has been widely evidenced in research, especially in patients with limited mobility $[12,13]$. The most important muscle group necessary to maintain independence in the activities of daily living are the muscles of the lower limbs [14]. The efficiency of the knee extensor muscles determines the ability to carry out such basic tasks as maintaining a standing position, walking, climbing and descending stairs, as well as rising from a sitting position. Walking speed, which is an indicator of independence in daily living activities, especially in the elderly, is dependent on the strength of the knee extensor muscles [15].

\section{Power}

In recent years, increasing interest has been focused on muscle power and muscle shortening velocity $[16,17]$. It has been reported that although muscle strength and power are strongly correlated with each other, they can determine functional efficiency to different degrees. Many activities of daily living require the capacity to perform short, relatively intensive exercises which demand the generation of appropriate muscle power-e.g. both force and some speed of movement [18]. Functional efficiency depends not only on how strong the muscles are, but also how quickly they can generate force [16]. This may be due to the fact that the activities of daily living require more complex muscle activity than just the slow development of strength [19]. Muscle shortening velocity, and hence, the ability to develop power, are closely related to the proportion of type II fibres [20]. This proportion decreases with advancing age and is accompanied by a slowing of muscle contraction, leading to a greater decline of maximal short-term power $\left(\mathrm{P}_{\max }\right)$ with age, and this decline is more closely related to the loss of functional abilities than the decrease of maximal muscle strength [3]. Limited data suggests that ageing is associated with a decrease in the optimal shortening velocity $\left(v_{\text {opt }}\right.$, a surrogate measure for muscle fibre type), i.e. the velocity corresponding to maximal power abilities in the muscles of the lower limbs [21,22]. Decreased quadriceps muscle $v_{\text {opt }}$ and $P_{\max }$ may cause gradually impaired functioning, and due to this impairment, many elderly subjects are approaching or reaching their functional threshold. In studies comparing the relationships of strength and muscle power to functional capacity, muscle power almost always appears to be a stronger determinant $[3,13,23]$. In elderly people, maximal muscle power is responsible to a greater extent for the variability of the results in functional tests than muscle strength, especially during low-intensity tasks such as walking [24]. The pace of walking is affected to some extent by muscle strength, but more by power and the shortening velocity of muscles $[25,26]$. The speed necessary for safely crossing the street is $\geq$ $1.2 \mathrm{~m} / \mathrm{s}$. Meanwhile, $84 \%$ of older men and $93 \%$ of women walk slower, which does not ensure traffic safety [27]. Of the two basic components of muscle power, velocity of contraction may affect functional performance to an even greater extent than strength [28,29]. For example, Mayson et al. [30] studied 138 elderly patients with physical disability in terms of the determinants of balance. Strength was found to correlate with two of the four performed balance tests, but velocity with three. This ability to maintain balance is of utmost importance in the prevention of falls in the elderly. There is the need for development, not only muscle strength but also speed of movement to prevent falls. In the Osteoporotic Fractures in Men Study, an association between fall-

*Corresponding author: Tomasz Kostka, Department of Geriatrics, Medical University of Lodz, Poland, E-mail: TomaszKostka@wp.pl

Received July 29, 2013; Accepted August 01, 2013; Published August 05, 2013

Citation: Kostka T, Kostka J (2013) May the Power Be With Us. Aging Sci 1: e102. doi: $10.4172 / 2329-8847.1000 \mathrm{e} 102$

Copyright: (C) 2013 Kostka T, et al. This is an open-access article distributed under the terms of the Creative Commons Attribution License, which permits unrestricted use, distribution, and reproduction in any medium, provided the original author and source are credited. 
related fractures and muscle power was identified in a group of 5995 men over 65 years old. In men with lower extensor muscle power in the lower extremities, a higher frequency of falls was observed within the 4 months before testing [31]. In another study, compared to persons who had not experienced a fall, elderly people who had experienced falls demonstrated $85 \%$ strength in the lower extremities (isometric, concentric and eccentric strength), and only $79 \%$ power, measured during bilateral lower extremity extension [32]. $v_{\text {opt }}$ i.e. the velocity at which muscle is able to develop its maximal power, seems crucial for short-term daily physical efforts which require development of power, such as standing up or climbing stairs. Clemencon et al. [29] studied the influence of strength, power and shortening velocity of the knee extensor muscles on the functional ability of elderly women. Muscle power and $v_{\text {opt }}$ correlated with functional tests, whereas no correlation of muscle strength was identified with the tests. The authors suggest that the assessment of power and $v_{\text {opt }}$ is a better indicator of functional capacity and mobility in older women than muscle strength. The rate and pattern of decline of muscle power and $v_{\text {opt }}$ with age may be different to that of muscle mass and force $[11,32,33]$. In one study, older men demonstrated a $40.3 \%$ lower $\mathrm{P}_{\max }$ than their almost 50 -year younger counterparts $(8.3 \%$ per decade). This decline was greater than the decrease in quadriceps mass (3.8\% per decade) [22]. The decline in $v_{\text {opt }}$ from youth to advanced age was $4.3 \%$ per decade [22]. The drop in $v_{\text {opt }}$ was visible already in the thirties and continued systematically until the eighties [33]. It has been suggested that the drop in muscle power might accelerate in advanced age. The age-related decrease pattern of $\mathrm{P}_{\max }$ reflects both the stabilization of anthropometric measures, such as quadriceps mass from youth to middle age and the systematic decline of $v_{\text {opt }}$ already from the thirties. Unlike muscle strength, power starts to decrease even after the fourth decade and becomes significantly lower earlier during adulthood. Although generally linear across the entire examined age range, the drop of $\mathrm{P}_{\max }$ seemed to accelerate in older subjects when compared to the preceding decade, and not reference values from subjects of 20-29 years old [33]. The decline of $\mathrm{P}_{\max } / \mathrm{kg}$ averaged $1.03 \%$ from the sixth to seventh decade of life, $1.42 \%$ from the seventh to eighth and $2.36 \%$ per annum from the eighth to ninth decade. Whether this acceleration in power decline really exists should be further explored in future studies with even more participants aged 80-100 years.

\section{Muscle Function is Debilitated in Many Diseases}

Many factors affecting muscle strength and power have been described so far. These include age, genetic factors, muscle crosssection, gender, malnutrition, health status and associated disease, behavioral factors such as levels of physical activity, smoking, hormonal factors, the concentration of vitamin $\mathrm{D}$, the concentration of cytokines, and even race [9,34-37]. Health status and concomitant diseases are associated with quality of muscle work. Concomitant diseases contribute to the limitation of physical activity, and as a consequence to further loss of muscle mass. The impact of cardiovascular diseases on muscle function is associated with lower blood flow, hypoxia and oxidative stress [36]. The reduction of muscle mass after stroke is largely dependent on reduced physical activity. Muscle weakness and loss of strength concern mainly the affected limbs, but apply to both sides $[38,39]$. The pain connected with the presence of osteoarthritis is the primary cause of reduced physical activity and associated decrease of muscle mass [36]. On the other hand, the reduction in muscle strength is considered as a risk factor for degenerative changes [40]. In patients with osteoarthritis, thigh muscle strength was found to be 16 to $27 \%$ lower as compared with their peers without any such symptoms [41].
Lower leg muscle power correlated with the presence of pain in the hip and knee [42]. Finally, pharmacotherapy may also influence muscle function. For example, long-term corticosteroid intake in patients with rheumatic diseases was associated with atrophy of type II fibers and a reduced capacity to generate muscle power [43].

\section{Preventive and Rehabilitative Measures}

Sustaining a satisfactory physical activity level and nutritional status, and effective treatment of accompanying diseases are cornerstones of proper neuromuscular function in advanced age. Physical activity is the most important way to improve muscle strength and power. The most effective means of training to increase muscle strength is resistance training, but aerobic training also enhances the function of muscles, affects the neural mechanisms responsible for the functioning of the muscles, stimulates protein synthesis and reduces body fat [34]. Thanks to these potential benefits, the ACSM recommends the inclusion of resistance training as part of an exercise program for older adults [44]. Increasing muscle strength without a significant increase of muscle mass is attributed to improved recruitment of motor units by the nervous mechanisms [45]. Improving muscle power is mainly due increases in their strength [46]. Increases in the velocity of muscle shortening can probably be explained by improved capacity to recruit fast muscle fibers. Future studies will concentrate on the efficacy and feasibility of power- and velocity-oriented training in subjects with different diseases and functional status. The training protocols in some studies that use higher-velocity training suggest that the gains in power may be greater than in classic resistance training [44]. Some benefits of speed training have already been described in highly functioning older adults, and in patients with early Parkinson's disease $[17,47,48]$. The optimization of the metabolic and hormonal environment for the generation of muscle power will be also an important challenge for future studies [49,50]. In conclusion, the aging of society is a phenomenon that mankind has never experienced before. The age-associated decline of physical functioning and increasing rate of disability in developed societies may well prove to be the most significant public health challenge in the coming years. Muscle power, with its two main components, i.e. muscle strength and muscle shortening velocity, is a key determinant of the functional status of older individuals. A growing body of scientific data clearly indicates that in advanced age, power means function. In the words of the Jedi Master Obi-Wan Kenobi, we should convey hope to our patients and ourselves in the ongoing struggle faced by Geriatric Medicine against functional decline and disability: "May the power be with us".

\section{References}

1. Abellan van Kan G, Rolland Y, Andrieu S, Bauer J, Beauchet O, et al. (2009) Gait speed at usual pace as a predictor of adverse outcomes in communitydwelling older people an International Academy on Nutrition and Aging (IANA) Task Force. J Nutr Health Aging 13: 881-889.

2. Rolland Y, Cances LV, Cesari M, Vellas B, Pahor M, et al. (2006) Physical performance measures as predictors of mortality in a cohort of communitydwelling older French women. Eur J Epidemiol 21: 113-122.

3. Bean JF, Leveille SG, Kiely DK, Bandinelli S, Guralnik JM, et al. (2003) A comparison of leg power and leg strength within the InCHIANTI study: Which influences mobility more? J Gerontol A Biol Sci Med Sci 58: 728-733.

4. Delbaere K, Close JC, Heim J, Sachdev PS, Brodaty H, et al. (2010) A multifactorial approach to understanding fall risk in older people. J Am Geriatr Soc Sep 58: 1679-1685.

5. Studenski S, Perera S, Wallace D, Chandler JM, Duncan PW, et al. (2003) Physical performance measures in the clinical setting. J Am Geriatr Soc 51: 314-322.

6. Blain H, Carriere I, Sourial N, Berard C, Favier F, et al. (2010) Balance and 
walking speed predict subsequent 8-year mortality independently of current and intermediate events in well-functioning women aged 75 years and older. $J$ Nutr Health Aging 14: 595-600.

7. Marcell TJ (2003) Sarcopenia: Causes, consequences and preventions. J Gerontol A Biol Sci Med Sci 58: 911-916.

8. Metter EJ, Lynch N, Conwit R, Lindle R, Tobin J, et al. (1999) Muscle quality and age: cross-sectional and longitudinal comparisons. J Gerontol A Biol Sci Med Sci 54: 207-218.

9. Jones EJ, Bishop PA, Woods AK, Green JM (2008) Cross-sectional area and muscular strength: A brief review. Sports Med 38: 987-994.

10. Visser M, Goodpaster BH, Kritchevsky SB, Newman AB, Nevitt M, et al. (2005) Muscle mass, muscle strength, and muscle fat infiltration as predictors of incident mobility limitations in well-functioning older persons. J Gerontol A Bio Sci Med Sci 60: 324-333.

11. Metter JE, Conwit R, Tobin J, Fozard JL (1997) Age-associated loss of power and strength in the upper extremities in women and men. J Gerontol A Biol Sci Med Sci 52: 267-276.

12. Ferrucci L, Guralnik JM, Buchner D, Kasper J, Lamb SE, et al. (1997) Departures from linearity in the relationship between measures of muscular strength and physical performance of the lower extremities: The Women's Health and Aging Study, J Gerontol A Biol Sci Med Sci 52: 275-285.

13. Puthoff ML, Janz KF, Nielson D (2008) The relationship between lower extremity strength and power to everyday walking behaviors in older adults with functional limitations. J Geriatr Phys Ther 31: 24-31.

14. Marsh AP, Miller ME, Rejeski WJ, Hutton SL, Kritchevsky SB (2009) Lower extremity muscle function after strength or power training in older adults. $J$ Aging Phys Activity 17: 416-443.

15. Bohannon RW (2008) Population representative gait speed and its determinants. J Geriatr Phys Ther 31: 49-52.

16. Bottaro M, Machado SN, Nogueira W, Scales R, Veloso J (2007) Effect of high versus low-velocity resistance training on muscular fitness and functional performance in older men. Eur J Appl Physiol 99: 257-264.

17. Hazell T, Kenno K, Jakobi J (2007) Functional benefit of power training for older adults. J Aging Phys Activity 15: 349-359.

18. Kostka T, Rahmani A, Berthouze SE, Lacour JR, Bonnefoy M (2000) Quadriceps muscle function in relation to habitual physical activity and VO2max in men and women aged>65 years. J Gerontol A Biol Sci Med Sci 55: 481-488.

19. Barry BK, Carson RG (2004) The consequences of resistance training for movement control in older adults. J Gerontol A Biol Sci Med Sci 59: 730-754.

20. Hautier CA, Linossier MT, Belli A, Lacour JR, Arsac LM (1996) Optimal velocity for maximal power production in non-isokinetic cycling is related to muscle fibre type composition. Eur J Appl Physiol 74: 114-118.

21. Kostka T, Bonnefoy M, Arsac LM, Berthoouze SE, Belli A, et al. (1997) Habitual physical activity and peak anaerobic power in elderly women. Eur J Appl Physiol 76: 81-87.

22. Bonnefoy M, Kostka T, Arsac LM, Berthouze SE, Lacour JR (1998) Peak anaerobic power in elderly men. Eur J Appl Physiol 77: 182-188.

23. Cuoco A, Callahan DM, Sayers S, Frontera WR, Bean J, et al. (2004) Impact of muscle power and force on gait speed in disabled older men and women. $J$ Gerontol A Biol Sci Med Sci 59: 1200-1206.

24. Foldvari M, Clark M, Laviolette LC, Bernstein MA, Kaliton D, et al. (2000) Association of muscle power with functional status in community-dwelling elderly women. J Gerontol A Biol Sci Med Sci 55: 192-199.

25. Marsh AP, Miller ME, Saikin AM, Rejeski WJ, Hu N, et al. (2006) Lower extremity strength and power are associated with 400-meter walk time in older adults: The InCHIANTI study. J Gerontol A Biol Sci Med Sci 61: 1186-1193.

26. Sayers SP (2008) High velocity power training in older adults. Curr Aging Sci 1: $62-67$

27. Asher L, Aresu M, Falaschetti EJM (2012) Most older pedestrians are unable to cross the road in time: A cross-sectional study. Age Ageing 41: 690-694.

28. Sayers SP, Guralnik JM, Thombs LA, Fielding RA (2005) Effect of leg muscle contraction velocity on functional performance in older men and women. J Am Geriatr Soc 53: 467-471.
29. Clemencon M, Hautier CA, Rahmani A, Cornu C, Bonnefoy M (2008) Potential role of optimal velocity as a qualitative factor of physical functional performance in women aged 72 to 96 years. Arch Phys Med Rehabil 89: 1594-1599.

30. Mayson DJ, Kiely DK, LaRose SI, Bean JF (2008) Leg strength or velocity of movement: Which is more influential on the balance of mobility limited elders? Am J Phys Med Rehabil 87: 969-976.

31. Chan BK, Marshall LM, Winters KM, Faulkner KA, Schwartz AV, et al. (2007) Incident fall risk and physical activity and physical performance among older men: the Osteoporotic Fractures in Men Study. Am J Epidemiol 165: 696-703.

32. Perry MC, Carville SF, Smith IC, Rutherford OM, Newham DJ (2007) Strength, power output and symmetry of leg muscles: Effect of age and history of falling Eur J Appl Physiol 100: 553-561.

33. Kostka T (2005) Quadriceps maximal power and optimal shortening velocity in 335 men aged 23-88 years. Eur J Appl Physiol 95: 140-145.

34. Rolland Y, Czerwinski S, Abellan Van Kan G, Morley JE, Cesari M, et al. (2008) Sarcopenia: Its assessment, etiology, pathogenesis, consequences and future perspectives. J Nutr Health Aging 12: 433-450

35. Sayer AA, Syddall H, Martin H, Patel H, Baylis D, et al. (2008) The developmental origins of sarcopenia. J Nutr Health Aging 12: 427-432.

36. Cesari M, Pahor M (2008) Target population for clinical trials on sarcopenia. J Nutr Health Aging 12: 470-478.

37. Norman K, Stobaus N, Smoliner C, Zocher D, Scheufele R, et al. (2010) Determinants of hand grip strength, knee extension strength and functional status in cancer patients. Clin Nutr 29: 586-591.

38. Gerrits KH, Beltman MJ, Koppe PA, Konijnenbelt H, Elich PD, et al. (2009) Isometric muscle function of knee extensors and the relation with functional performance in patients with stroke. Arch Phys Med Rehabil 90: 480-487.

39. English C, McLennan H, Thoirs K, Coates A, Bernhardt J (2010) Loss of skeletal muscle mass after stroke: A systematic review. Int J Stroke 5: 395-402.

40. Thorlund JB, Aagaard P, Roos EM (2010) Thigh muscle strength, functional capacity, and self-reported function in patients at high risk of knee osteoarthritis compared with controls. Arthritis Care Res (Hoboken) 62: 1244-1251.

41. Hinman RS, Hunt MA, Creaby MW, Wrigley TV, McManus FJ, et al. (2010) Hip muscle weakness in individuals with medial knee osteoarthritis. Arthritis Care Res (Hoboken) 62: 1190-1193.

42. Cecchi F, Mannoni A, Lova MR, Ceppatelli S, Benvenuti E, et al. (2008) Epidemiology of hip and knee pain in a community based sample of Italian persons aged 65 and older. Osteoarthritis Cartilage 16: 1039-1046.

43. Rothstein JM, Delitto A, Sinacore DR, Rose SJ (1983) Muscle function in rheumatic disease patients treated with corticosteroids. Muscle Nerve Supp 6: 128-135.

44. Zajko CWJ, Proctor DN, Fiatarone Singh MA, Minson CT, Nigg CR, et al. (2009) American College of Sports Medicine position stand. Exercise and physical activity for older adults. Med Sci Sports Exerc 41: 1510-1530.

45. Gabriel DA, Kamen G, Frost G (2006) Neural adaptations to resistive exercise: mechanisms and recommendations for training practices. Sports Med 36: 133149

46. Porter MM (2006) Power training for older adults. Appl Physiol Nutr Metab 31 87-94.

47. de Vos NJ, Singh NA, Ross DA, Stavrinos TM, Orr R, et al. (2008) Effect of power-training intensity on the contribution of force and velocity to peak power in older adults. J Aging Phys Activity 16: 393-407.

48. Pohl M, Rockstroh G, Rückriem S, Mrass G, Mehrholz J (2003) Immediate effects of speed-dependent treadmill training on gait parameters in early Parkinson's disease. Arch Phys Med Rehabil 84: 1760-1766.

49. Kostka T, Arsac LM, Patricot MC, Berthouze SE, Lacour JR, et al. (2000) Leg extensor power and dehydroepiandrosterone sulfate, insulin-like growth factorand testosterone in healthy active elderly people. Eur J Appl Physiol 82: 83-90.

50. Giannoulis MG, Martin FC, Nair KS, Umpleby AM, Sonksen P (2012) Hormone replacement therapy and physical function in healthy older men. Time to talk hormones? Endocr Rev 33: 14-377. 